\title{
THE INFLUENCE OF MYCOPLASMA INFECTION ON THE SENSITIVITY OF HELA CELLS FOR GROWTH OF VIRUSES
}

\author{
F. D. Hargreaves and R. H. Leach \\ Virus Reference Laboratory and Mycoplasma Reference Laboratory, \\ Central Public Health Laboratory, Colindale Avenue, London
}

Cell cultures are extremely susceptible to contamination with mycoplasmas and this contamination is a particular problem with stable cell lines, which can be propagated indefinitely and are used as a routine for cultivation of many animal viruses (Hayflick, 1965; Macpherson, 1966).

Several different mycoplasma species have been isolated from such cell lines before their inoculation with virus material. The most commonly occurring species appear to be Mycoplasma hominis, $M$. orale type 1 ( $M$. pharyngis) and $M$. hyorhinis (Macpherson; Purcell et al., 1966; Hayflick and Stanbridge, 1967). These findings have been confirmed by us and suggest that most cell lines used in virus investigations are probably contaminated with one of the three species. Macpherson has pointed out that such contamination produces several problems for the virologist. Contamination with some mycoplasmas, particularly $M$. hyorhinis, may make the cell cultures difficult to maintain and may produce changes in cells that may be confused with the cytopathic effects of viruses (Butler and Leach, 1964). In addition it is clear that cell lines contaminated with mycoplasmas should not be used in biochemical studies of viruses, since the mycoplasmas may alter the metabolism of the virus-infected cells (Macpherson; Neufahrt, Rolly and Schutze, 1969). The presence of mycoplasmas would also seem to be undesirable in serological studies of viruses.

A question of considerable practical importance, about which more information is needed, is the extent to which contamination with mycoplasmas may interfere with multiplication of viruses in cell cultures. Several reports, dealing primarily with attempts to remove mycoplasma contamination from cell lines, have mentioned the effects of the contamination on virus growth (Brownstein and Graham, 1961; Herderschee, Ruys and Rhijn, 1963; Gori and Lee, 1964; O'Connell, Wittler and Faber, 1964) and have indicated that these effects, if detectable, were only slight. Depressed haemagglutination titres were observed in suspensions of arbovirus and vaccinia virus grown in mycoplasma-infected cells (Kagan et al., 1968). Growth of adenovirus, which fails to mature in arginine-deprived cell cultures, was suppressed in cell lines contaminated with an unidentified, but demonstrably arginineutilising, mycoplasma (Rouse, Bonifas and Schlesinger, 1963). A marked reduction in the sensitivity of a contaminated cell line used for titration of adenovirus has also been reported (Kagan et al.). The effect of mycoplasma contamination on herpesviruses and papovaviruses, which also require arginine for replication (Becker, Olshevsky and Levitt, 1967; Goldblum, Ravid and Becker, 1968), does not appear to have been investigated.

In a few instances, an effect on virus growth has been reported after deliberate introduction of known mycoplasmas into cell lines. $M$. orale type 1 and $M$. hominis suppressed the growth of Rous sarcoma virus in chick and human embryo cell cultures (Somerson and Cook, 1965; Macpherson). Kagan (1967) demonstrated that deliberate infection with $M$. hominis and several other mycoplasma species reduced the yield of several arboviruses and a myxovirus in chick embryo cell cultures. Titres of vesicular stomatitis virus growing in primary hamster fibroblast cell cultures were enhanced by simultaneous infection with M. arginini (Singer, Kirschstein and Barile, 1969).

Received 2 Aug. 1969; accepted 16 Sept. 1969.

J. MED. MICROBIOL.--VOL. 3 (1970) 
It is important to know to what extent the widespread use of mycoplasmacontaminated cell lines interferes with virus multiplication in diagnostic procedures. In this report the effects of infection with three recognised mycoplasma species on the sensitivity of a HeLa cell line have been studied by testing the growth of a number of different animal viruses. Pools of each virus were titrated in HeLa cell cultures in the presence and absence of each of the three mycoplasmas. Titres were estimated on the basis of the cytopathic effects observed.

\section{MATERIALS AND METHODS}

Viruses. The viruses were selected from the main groups that affect man, and included adenovirus, herpesvirus, myxovirus, picornavirus and poxvirus. Prototype strains of adenovirus types 2 and 31, herpes simplex virus and Sabin's attenuated type-1 strain of poliovirus were used, but the parainfluenza type- 2 virus, respiratory syncytial virus and vaccinia virus strains had been recently isolated in monkey kidney cell cultures. Pools of the viruses in mycoplasma-free $\mathrm{HeLa}$ culture fluids were stored at $-70^{\circ} \mathrm{C}$ in sealed ampoules and one ampoule of each virus was thawed for each experiment.

Mycoplasmas. The three species tested were $M$. orale type 1, strain M482/67, $M$. hominis " type 1", strain M486/67, and M. hyorhinis, strain M463/67. The strain of each species employed had been isolated from a cell line and purified by subculture from a discrete single colony on agar.

Cell lines. A line of HeLa cells free from detectable mycoplasmas was used. It had been treated with kanamycin some years previously and repeated tests for mycoplasmas made thereafter had been consistently negative. The test cells were divided into four sublines. One of these lines was inoculated with $M$. orale type 1 , one with $M$. hominis and one with $M$. hyorhinis. After a few passages, heavy infection of each subline with its strain of mycoplasma could be consistently demonstrated. The fourth HeLa subline was maintained as a mycoplasma-free control culture. All four sublines were repeatedly tested for the presence or absence of mycoplasmas. The serological identity of each strain of mycoplasma was also confirmed at intervals.

Tests for the presence of mycoplasmas. HeLa culture fluids containing cells either scraped or shaken from a glass tube were inoculated on a mycoplasma medium. Approximately $0 \cdot 1-\mathrm{ml}$ amounts of fluid were plated on at least two agar plates of a special enriched agar medium containing PPLO agar base, 10 per cent. heat-inactivated human serum, 10 per cent. extract of boiled ox blood, 10 per cent. boiled yeast extract $(25 \mathrm{~g}$ per $100 \mathrm{ml}), 0.002$ per cent. DNA, penicillin 100 units per $\mathrm{ml}$, and 0.025 per cent. thallous acetate. This medium was consistently superior to standard horse serum agar (Hayflick) for the isolation and growth of many mycoplasmas (Andrews, 1969). After inoculation, the plates were incubated at $37^{\circ} \mathrm{C}$ both aerobically and in an atmosphere of 5 per cent. $\mathrm{CO}_{2}$ in nitrogen. A further $0.1-0.3 \mathrm{ml}$ of the cell culture fluid was inoculated into $3 \mathrm{ml}$ of standard PPLO horse serum broth (Hayflick). If no colonies were visible on either of the inoculated agar plates after 4-6 days' incubation, the broth culture was subcultured on agar, which was examined for colonies up to 10 days. Any mycoplasmas isolated from the cell cultures were identified by the filter paper disk growth inhibition test (Clyde, 1964) with specific rabbit antiserum for each mycoplasma species.

Experimental procedures. The HeLa cells were grown in stationary bottles with Gey's medium containing 10 per cent. human serum, 0.5 per cent. lactalbumin hydrolysate, penicillin 100 units per $\mathrm{ml}$, and streptomycin $100 \mu \mathrm{g}$ per ml. When confluent, the cell sheets were trypsinised and glass tubes $(10 \times 1.5 \mathrm{~cm})$ were each seeded with 50,000 cells suspended in $0.5 \mathrm{ml}$ volumes of growth medium containing 5 per cent. inactivated rabbit serum instead of human serum. The tubes were incubated for $24 \mathrm{hr}$ at $37^{\circ} \mathrm{C}$, after which another $0.5 \mathrm{ml}$ of the same growth medium without lactalbumin hydrolysate was added to each of them. The tubes were re-incubated until, usually after a further $24-48 \mathrm{hr}$, the cell sheets became confluent. They were then used for the virus titrations. 
On each occasion, one ampoule of the required virus was thawed quickly and diluted in Gey's medium in $0.5 \log _{10}$ steps over a suitable range. $0.1-\mathrm{ml}$ volumes of each dilution were inoculated into HeLa cell culture tubes in triplicate. Simultaneous titrations were done in the four HeLa sublines. The tubes were then incubated in stationary racks at $37^{\circ} \mathrm{C}$. Tubes were examined on alternate days for cytopathic effects characteristic of each virus. The subline infected with $M$. hyorhinis tended to acidify more rapidly than the other sublines and in order to avoid excessive acidification and deterioration of the cells it was necessary to replace the cell fluids with fresh maintenance medium at least every 7 days. The other three cell fluids were changed at the same time. The maintenance medium was Gey's medium containing 5 per cent. inactivated rabbit serum, $0 \cdot 25$ per cent. lactalbumin

TABLE

Effect of infection with mycoplasmas on the titre of viruses grown in HeLa cells

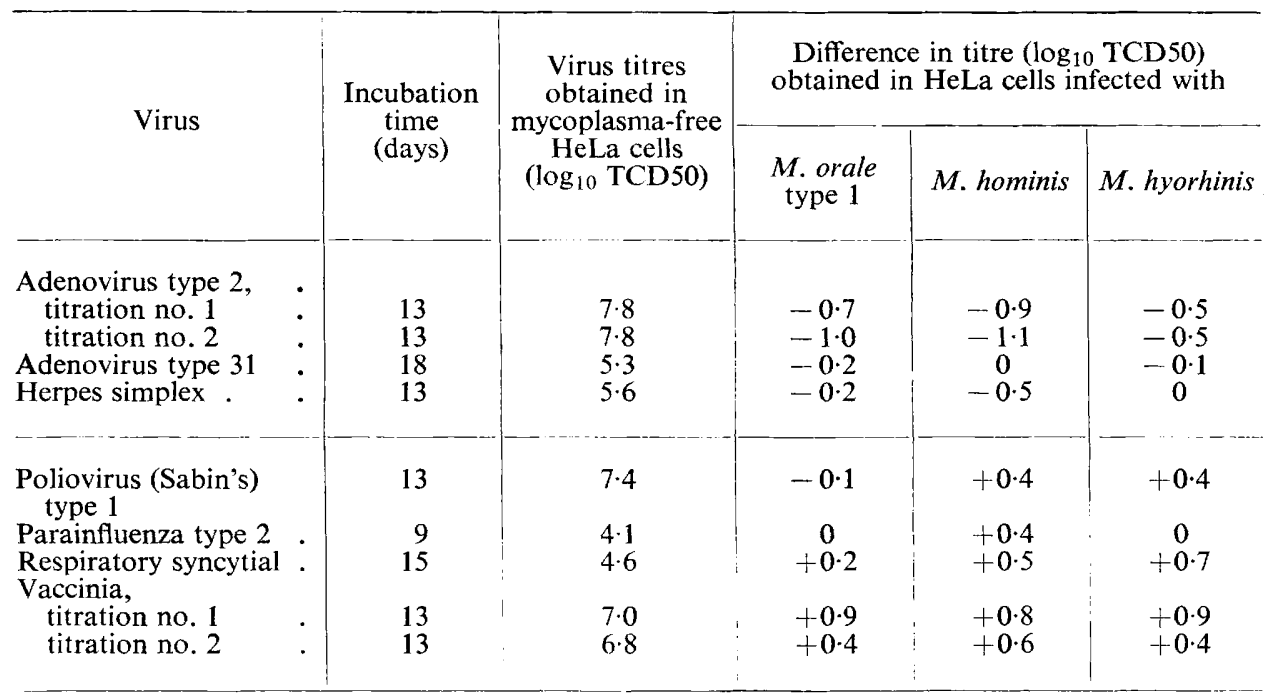

hydrolysate, penicillin 100 units per $\mathrm{ml}$, and streptomycin $100 \mu \mathrm{g}$ per $\mathrm{ml}$. Fifty per cent. infecting doses (TCD50) were estimated by the method of Reed and Muench (1938).

\section{RESULTS}

The results of titrating each virus in the four HeLa sublines are set out in the table. The $\log _{10}$ titres obtained in mycoplasma-free cells are given and the other figures shown are the differences in titre obtained in each mycoplasmainfected subline. From these results, the viruses could be divided into two groups. Titres for the group consisting of herpes simplex virus and the two adenoviruses were usually lower in HeLa cells infected with the three mycoplasmas than in uninfected HeLa cells. The effects were greatest with adenovirus type 2 and minimal with adenovirus type 31 . The reduction in virus titres was more pronounced in cells infected with $M$. orale type 1 or $M$. hominis than in those infected with M. hyorhinis. With the other group of viruses, which consisted of vaccinia, polio type 1 , parainfluenza type 2 , and respiratory syncytial viruses, the results showed the opposite trend. The virus titres tended to be 
higher in mycoplasma-infected HeLa cells than in the uninfected ones. There were no consistent differences in effect between the different mycoplasmas.

In the case of adenovirus type 2 and vaccinia virus, which showed the largest effects for either group in the initial experiments, repeated titrations on the same virus pool confirmed the direction, but not the magnitude, of the effects. The differences in titres obtained between repeated titrations were approximately consistent with the expected degree of accuracy of the three-tube half-log. titration method used in the experiments. Titres of adenovirus type 2 and herpes simplex virus after 13 days are not included in the table. After about the first two weeks it becomes increasingly difficult to maintain the cells infected with $M$. hyorhinis and to distinguish clearly the cytopathic effects caused by the mycoplasma from those due to the herpes- and adeno-viruses. However, virus titres in the other two mycoplasma-infected sublines, and in subcultures made from them on the 25 th day after inoculation, confirmed the trends shown in the table.

Tests for the presence of mycoplasmas, which were carried out several times during the experiments, showed that the control HeLa subline remained free from mycoplasmas. Positive results were obtained in every case when the mycoplasma-infected sublines were tested, irrespective of the presence or absence of virus or of the age or state of the tissue cultures when examined. In most cases a heavy growth of mycoplasma colonies was obtained by direct inoculation of cell cultures on the solid medium. At intervals during the experiment and at the end of the experiment, the identities of the mycoplasmas isolated from the three infected sublines were confirmed by growth inhibition tests as $M$. orale type $1, M$.hominis and $M$. hyorhinis. There was no evidence of cross-contamination with different mycoplasmas.

\section{DISCUSSION}

The influence of mycoplasma infection in Hela cell cultures on the titres of virus grown in these cultures differed with the different viruses tested. The titres of some viruses were enhanced and those of others reduced. The effects in some cases were very small and it is doubtful whether individual differences in $\log _{10}$ titre of less then 0.5 are significant. Differences greater than $0.5\left(\log _{10}\right)$ were obtained only with adenovirus type 2 , vaccinia virus and respiratory syncytial virus. In the table an indication of the order of accuracy to be expected is evident from the considerable variation observed in repeat titrations of adenovirus type 2 and vaccinia virus. The results indicate that mycoplasma infection of a HeLa cell line can interfere with its usefulness in the titration of some viruses.

The two virus species adversely affected by mycoplasma contamination were herpesvirus and adenovirus, both of which have a specific requirement for arginine (Rouse et al., 1963; Becker et al., 1967). The most marked effects were seen with adenovirus type 2 . This finding was not unexpected for cells infected with $M$. hominis or $M$. orale type 1 , mycoplasmas that possess an arginine hydrolase system (Barile, Schimke and Riggs, 1966). Inhibition of the development of adenovirus type 2 in cell lines contaminated with an unidentified arginineutilising mycoplasma has been shown to be associated with depletion of arginine 
in cell cultures by the mycoplasma (Rouse et al.). However, the adverse effect of $M$. hyorhinis on the titres of adenovirus cannot be attributed to this cause since $M$. hyorhinis does not possess an arginine hydrolase system (Barile et al., 1966). Other influences besides competition for arginine may be responsible for the inhibition of these viruses by mycoplasmas, because there have been reports (Macpherson, 1966; Kagan, 1967) of inhibition of viruses with no known arginine requirement by both arginine-utilising and non-arginine-utilising mycoplasmas. The papovavirus group also appears to require arginine for replication (Goldblum et al., 1968), but none of these viruses could be included in our tests.

The growth of viruses of the enterovirus, myxovirus and poxvirus groups was enhanced by infection of the HeLa cells with any of the three mycoplasmas. Except for vaccinia virus and, possibly, respiratory syncytial virus, the effects were relatively small. Similar results with vaccinia virus were reported by Kagan et al. (1968).

End-point titration based upon observation of the cytopathic effects of viruses on cell cultures is a relatively crude method of estimating virus titres and is probably not very suitable for studying the various factors involved in virus-mycoplasma interactions. With adenovirus, Rouse et al. found that plaque formation was a very sensitive indicator of the inhibitory effect of mycoplasma infection of the cell culture and this technique might usefully be applied to other plaque-forming viruses. However, our own preliminary studies on the yield of adenovirus grown in HeLa cells have indicated that titres of infectious virus and virus haemagglutinin were not appreciably affected by contamination with $M$. hominis.

The aim of these investigations was to assess the importance of mycoplasma contamination of a HeLa cell line on its usefulness for the titration and isolation of viruses. The main finding was that differences in virus titres, whether positive or negative, were relatively small, usually less than ten-fold. For critical work with particular viruses, such differences may be significant. Although small differences in the sensitivity of the cell line might also be important for isolation of a virus that was present only in small numbers in a clinical specimen, it is probable that other factors, such as the composition of the tissue-culture medium and, more particularly, the nature and quality of the serum component, may have a greater influence than mycoplasma contamination on the ability of the cells to support virus growth.

The present experiments were carried out with only three species of mycoplasmas, $M$. hominis, $M$. orale type 1 and $M$. hyorhinis, which are regarded as the commonest contaminants of cell lines. Other species, such as $M$. laidlawii and a newly discovered arginine-hydrolysing mycoplasma, $M$. arginini, are also frequently present in tissue cultures (Hayflick and Stanbridge, 1967; Barile et al., 1968) and it would be interesting to examine the effects of these and other species on the growth of representative viruses. Singer et al. (1969) have recently reported an enhancing effect of $M$. arginini on titres of vesicular stomatitis virus grown in primary hamster fibroblast cell cultures. The mycoplasmas likely to cause problems in virological procedures will normally be those present 
in the uninoculated cell lines, but it must be remembered that many types of clinical specimen inoculated into tissue cultures for virus isolation may also contain mycoplasmas. Although largely uninvestigated, this potential source of contamination presents an additional hazard and suggests a further reason for investigating the effects of a wider range of mycoplasmas of both human and animal origin.

It is obviously necessary to avoid the use of tissue cultures contaminated with cytopathic mycoplasmas such as $M$. hyorhinis, whose ability to cause severe degeneration of cells under some circumstances (Butler and Leach, 1964) was confirmed in our experiments. We found that cells infected with $M$. hyorhinis were particularly unsuitable for titration of viruses requiring a long period of incubation, e.g., adenovirus, because of the difficulties encountered in maintaining the cells and in distinguishing between cytopathic effects of virus and mycoplasma in the later stages of incubation. On the evidence of present tests, however, it seems unlikely that other mycoplasmas, such as $M$. hominis and $M$. orale type 1 , would represent a serious hazard in routine diagnostic virology.

\section{SUMMARY}

Three sublines of HeLa cells were infected with Mycoplasma orale type 1, $M$. hominis and $M$. hyorhinis and compared with mycoplasma-free cells for their ability to support the growth of adenovirus types 2 and 31 , herpes simplex virus, Sabin's poliovirus type 1 , parainfluenza virus type 2 , respiratory syncytial virus and vaccinia virus. Titres of herpesvirus and adenovirus tended to be reduced in the cells infected with mycoplasmas, but titres of the other viruses were generally raised by such infection. The largest differences in titre in either direction were approximately ten-fold and were obtained with adenovirus type 2 (reduction) and vaccinia virus (increase). Much smaller effects were noted with the other viruses.

With herpesviruses and adenoviruses, which have a known requirement for arginine, the antagonistic effect of the two arginine-metabolising mycoplasmas, $M$. orale type 1 and $M$. hominis, was more than that of $M$. hyorhinis, which does not metabolise arginine. With the other viruses, the higher titres obtained in the mycoplasma-infected cells were independent of the species of mycoplasma. The cell lines infected with $M$. hyorhinis were difficult to maintain for long periods on account of the cytopathic effects of this species, and were, therefore, less suitable for titration of the more slowly growing herpes- and adeno-viruses.

It is concluded that mycoplasma contamination of a HeLa cell line may interfere with the titration of some viruses, but the effects are relatively small and probably do not constitute a serious hazard in routine diagnostic virology.

We are greatly indebted to Dr Marguerite S. Pereira for her very valuable technical advice and aid throughout this investigation. We are also grateful for the helpful interest of Dr B. E. Andrews, at whose suggestion the investigation was undertaken. A preliminary account of part of this work was reported at the International Symposium on Mycoplasma Diseases of Man, Erfurt, East Germany, October 1968. 


\section{REFERENCES}

ANDREws, B. E. $\quad$ - . . . . . 1969. In Mycoplasma diseases of man, ed. by

Barile, M. F. Delgiudice, R A 1968. Proc. Sprossig and W. Witzleb, Jena.

CARSKI, R. T., GibBS, C. J., AND

MORRIS, J. A.

Barile, M. F., Schimke, R. T., AND 1966. J. Bact., 91, 189.

RIGGS, D.

Becker, Y., Olshevsky, U., and Levitt, 1967. J. Gen. Virol., 1, 471. J.

Brownstein, B., and Graham, A. F. . 1961. Virology, 14, 303.

BUtLER, M., AND LEACH, R. H. . . . 1964. J. Gen. Microbiol., 34, 285.

Clyde, W. A., JR . . . . . . . . . 1964. J. Immun., 92, 858.

Goldblum, N., Ravid, Z., AND Becker, 1968. J. Gen. Virol., 3, 143.

$Y$.

Gori, G. B., AND Lee, D. Y. . . . 1964. Proc. Soc. Exp. Biol. Med., 117, 918.

HaYflick, L. . . . . . . . . . 1965. Tex. Rep. Biol. Med., 23, 285.

Hayflick, L., and Stanbridge, E. . . 1967. Ann. N.Y. Acad. Sci., 143, 608.

Herderschee, D., RuYs, A. C., AND 1963. Antonie van Leeuwenhoek, 29, 386. VAN RHIJN, G. R.

Kagan, G. Y. . . . . . . . . . . 1967. Ann. N.Y. Acad. Sci., 143, 734.

Kagan, G. Y., Kulikova, K. S., Nue- 1968. Vop. Virus, 13, 600. Stroeva, V. V., Rezepova, A. I., AND Sultanova, Z. D.

Macpherson, I. . . . . . . . . 1966. J. Cell Sci., 1, 145.

Neufahrt, A., Rolly, H., and Schutze, 1969. Zentbl. Bakt. ParasitKde, Abt. I, Orig., E.

O'Connell, R. C., Wittler, R. G., AND 1964. Appl. Microbiol., 12, 337. FABER, J. E.

Purcell, R. H., Somerson, N. L., Fox, 1966. J. Natn. Cancer Inst., 37, 251. H., WONG, D. C., TURNer, H. C., AND CHANOCK, R. M.

Reed, L. J., ANd Muench, H. . . 1938. Amer. J. Hyg., 27, 493.

Rouse, H. C., Bonifas, V. H., aNd 1963. Virology, 20, 357. SCHLESINGER, R. W.

Singer, S. H., KirSchstein, Ruth L., 1969. Nature, Lond., 222, 1087. AND BARILE, M. F.

Somerson, N. L., AND CoOK, M. K. 1965. J. Bact., 90, 534. 